\title{
Brucellosis Vaccines for Livestock
}

Zakia I. Goodwin, David W. Pascual ${ }^{*}$

Department of Infectious Diseases \& Pathology, College of Veterinary Medicine, University of Florida, Gainesville, FL, United States

Correspondence: Department of Infectious Diseases \& Pathology, University of Florida, 1945 S.W. $16^{\text {th }}$ Ave., Gainesville, FL 32608.

Tel.: +1 352294 4104; FAX: +1 3523929704

E-mail: pascuald@ufl.edu

Key words: Brucella, livestock, vaccine, immunity, mucosal 


\section{Abstract}

Brucellosis is a livestock disease responsible for fetal loss due to abortions. Worldwide, this disease has profound economic and social impact by reducing the ability of livestock producers to provide an adequate supply of disease-free meat and dairy products. In addition to its presence in domesticated animals, brucellosis is harbored in a number of wildlife species creating new disease reservoirs, which adds to the difficulty of eradicating this disease. Broad and consistent use of the available vaccines would contribute in reducing the incidence of brucellosis. Unfortunately, this practice is not common. In addition, the current brucellosis vaccines cannot provide sterilizing immunity, and in certain circumstances, vaccinated livestock are not protected against co-mingling Brucella-infected wildlife. Given that these vaccines are inadequate for conferring complete protection for some vaccinated livestock, alternatives are being sought, and these include genetic modifications of current vaccines or their reformulations. Alternatively, many groups have sought to develop new vaccines. Subunit vaccines, delivered as a combination of soluble vaccine plus adjuvant or the heterologous expression of Brucella epitopes by different vaccine vectors are currently being tested. New live attenuated Brucella vaccines are also being developed and tested in their natural hosts. Yet, what is rarely considered is the route of vaccination which could improve vaccine efficacy. Since Brucella infections are mostly transmitted mucosally, mucosal delivery of a vaccine has the potential of eliciting a more robust protective immune response for improved efficacy. Hence, this review will examine these questions and provide the status of new vaccines for livestock brucellosis. 


\section{Introduction}

Brucellosis is a contagious bacterial disease of livestock caused by the facultative intracellular pathogen Brucella (Whatmore, 2009). While brucellosis outbreaks have a major economic impact on livestock production, the disease is also a true zoonosis and is actually the most common zoonotic disease worldwide causing debilitating and sometimes chronic disease in humans (Pappas et al., 2006; Köse et al., 2014). Brucella infection in livestock is characterized by late term abortions, placental retention, metritis and reduced milk production (Glynn and Lynn, 2008; Blasco and Molina-Flores, 2011). Most infected cows will only abort once, but will remain as a source of infection during subsequent normal calving due to heavily infected placentas. In swine, the disease is clinically silent in most cases, but when apparent, it is characterized by abortion at any stage of gestation and animals may additionally manifest orchitis, lameness and hind-limb paralysis (Glynn and Lynn, 2008; Plilo et al., 2015).

Brucella species can also infect wildlife, and the classical Brucella species have been isolated from a great variety of wildlife species such as bison, elk, feral swine, wild boar, fox, hare, African buffalo, reindeer, and caribou (Godfroid et al., 2013). Although the pathogenesis of brucellosis in wild-life reservoirs is not yet fully defined (Godfroid et al., 2010), the disease has been observed to cause abortions in bison and elk (Davis et al., 1991; Palmer et al., 1996; Kreeger et al., 2002a).

Human brucellosis manifests in acute form as varying, nonspecific symptoms such as undulating fever, malaise and joint pain (Köse et al., 2014). Treatment failure, which occurs in 5$15 \%$ of cases, can result in chronic infection characterized by severe complications of the nervous system, musculoskeletal system and the heart (Franco et al., 2007). More than 500,000 cases of human brucellosis are reported annually; however, where it is endemic, cases of brucellosis are believed to be severely underreported by as much as eleven-fold (Bonfoh et al., 
2012). True incidence of human brucellosis is unknown and the estimated burden of the disease varies widely, from $<0.03$ to $>160$ per 100,000 population (Pappas et al., 2006).

Vaccination is an effective method to reduce disease incidence in livestock which correlates to a decrease in the number of reported human cases. Antibiotics are mostly effective in resolving human brucellosis, but treatment can be arduous requiring simultaneous use of two different antibiotics for up to two months, and still resulting in $16 \%$ of individuals to remain infected (Ariza et al., 1995). Moreover, there are no vaccines available for humans, and livestock vaccines are reactogenic to humans (Spink et al., 1962; Ashford et al., 2004; World Animal Health Organization, 2014). Existing Brucella vaccines for livestock have several drawbacks; hence, the design and development of safer, more effective vaccines is an ongoing endeavor. A full appreciation of the host-pathogen relationship is required for successful vaccine design and development. Also equally important in developing new vaccines is determining the delivery mechanism and route of vaccination which will provide the maximum protective response.

\section{Brucella Distribution and Impact}

Brucella has a worldwide distribution with different species varying in geographic distribution. B. abortus is found worldwide where cattle production occurs except in Japan, Canada, portions of Europe, Australia, New Zealand, and Israel, where it has been eradicated (Seleem et al., 2010). In the USA, Brucella has been mostly eradicated from domestic cattle, but it is still problematic in the Greater Yellowstone Area (GYA) that encompasses Yellowstone and Grand Teton National Parks (Clifford, 2008). The free-ranging bison and elk continue to serve

as a reservoir for $B$. abortus in the GYA. B. suis is also problematic for cattle and livestock in Florida and in the mid-West due to feral pigs (Leiser et al., 2013). 
Though the actual prevalence is not known, Brucella currently affects the entire African continent, and it is traditionally considered to be endemic in North Africa with heavy repercussions in public health, food safety, and food security (Hotez et al., 2012). Both $B$. abortus and B. suis have been identified in all countries in Central America although they are not considered to be endemic except in Guatemala and Panama (Pappas et al., 2005). In several South American countries, bovine brucellosis is also endemic and affects the large livestock production industry of some countries such as Argentina, where an estimated $50 \%$ of dairy farms are reported to be affected (Aznar et al., 2014). Several European Union countries including Sweden, Germany, and France have managed to successfully eradicate Brucella as a result of adequate surveillance and eradication programs. Other countries such as Spain and Portugal remain endemic though eradication efforts are underway. Greece, on the other hand, has one of the highest Brucella incidences worldwide (Pappas et al., 2005).

Middle Eastern countries are historically endemic for Brucella with Syria presenting the highest incidence worldwide (Pappas et al., 2005). Brucella in China is endemic and recent changes in geographical distribution have resulted in the spread of the disease to southern provinces. However major efforts are ongoing to reverse this trend (Memish and Balkhy, 2006). Brucella is also endemic in India and Pakistan though detailed data on incidence is not available (Pappas et al., 2005).

The economic impact of brucellosis is severe and is related to losses in animal production due to trade restrictions, decreases in milk production, fertility losses, as well as public health costs related to diagnosis, treatment, and decreased productivity in affected persons. One example is Latin America where official estimates of annual losses due to bovine brucellosis are approximately $\$ 600$ million (Seleem et al., 2010).

B. melitensis, B. suis, and B. abortus are listed as potential bio-weapons by the Centers for Disease Control and Prevention (CDC) in the USA. This is due to the highly infectious nature 
of all three species in humans, the fact that they can be readily aerosolized and the high cost of treatment (Seleem et al., 2010).

\section{Biology and Clinical Disease}

The Brucella genus are Gram (-) alpha-proteobacteria and represent a group comprised of at least 10 species of coccobacilli named primarily after their preferred host organism or symptoms of infection: B.abortus, B. melitensis, B. suis, B. ovis, B. canis, B. neotome, B microti, B. inopinata, B. pinnipedialis, and B ceti (Haag et al., 2010). These species are genetically highly related to each other, exhibiting DNA sequence similarity values of $98 \%$ to $100 \%$ in aligned regions (core genome), but can be clearly distinguished from each other by application of high-resolution molecular typing tools, in addition to assessment of phenotype and host range (Haag et al., 2010; Scholz and Vergnaud, 2013). They can also be distinguished serologically due to differences in their LPS expression.

The ability of Brucella spp to effectively avoid extracellular killing, invade host cells and successfully, colonize and multiply is related to evolutionary mechanisms developed by the organism designed to avoid the host immune response and to enhance survival within its target host. Unlike other Gram (-) bacteria, Brucella expresses a "non-classical LPS" on the outer layer of its cell-wall which behaves as a major virulence factor for this pathogen (Haag et al., 2010). The LPS makes the brucellae highly resistant to cationic bacterial peptides and also inhibits complement-mediated killing by blocking access of $\mathrm{C} 1 \mathrm{q}$ to the outer membrane targets thus enhancing survival in the extracellular environment. The noncanonical structure (long chain acyl groups on the lipid A) of the Brucella LPS also results in a decreased inflammatory response via interaction with the toll-like receptor TLR4 which further enhances survival (Neta et al., 2010).

Once the brucellae invade the host cell, specific survival mechanisms are activated to avoid the host's natural defense mechanisms. The type IV secretion complex and the 
BvrR/BvrS two-component regulatory systems as well as the LPS structure all enhance intracellular survival. This is achieved by preventing the fusion of the phagosome/endosome with the lysosome, controlling the expression of outer membrane proteins (OMPs) and preventing MHC II-peptide expression on the outer cell surface (Guzmán-Verri et al., 2002; Celli et al., 2003). Unique pathways to access various nutrients are also utilized by Brucella to facilitate its long-term survival within the host (Roop et al., 2009). Although macrophages are the preferred host cell target, the Brucella pathogen is also able to infect non-phagocytic cells, epithelial cells, respiratory tissues, and male and female reproductive tissues along with other tissue types (Xavier et al., 2009; Roop et al., 2009).

In bovine brucellosis, this pathogen demonstrates tropism for the placenta, and in fact, B. abortus can replicate to large numbers as found in aborted fetuses and placentas. A study conducted in cows, experimentally infected with $B$. abortus, found the pathogen mostly confined to the fetal cotyledons, fluids, and chorion containing $60-85 \%, 1-25 \%$, and $2-8 \%$, respectively, of the total number of organisms found in the mother and fetus (Scholz and Vergnaud, 2013). Erythitol acts as a unique carbon source for bacterial metabolism, and it has been shown to stimulate the growth of Brucella abortus both in vitro (Smith et al., 1962a) and in 1-5 day old calves (Smith et al., 1962b). In normal bovine fetuses, erythitol is present and concentrated in the chorion, cotyledons, and fetal fluids. These studies suggest that erythitol is a major factor which enhances the susceptibility of the bovine reproductive tract to infection with $B$. abortus. The localized presence of erythritol in the reproductive tissues in the bull, ram, goat, and boar provide further evidence of its contribution to the localization of infection in the genitalia in these species. The absence of erythitol in the placenta or seminal vesicles of species such as humans, who are not susceptible to acute placentitis or orchitis in brucellosis, further corroborates this theory (Williams et al., 1964). 
Further characterization of placentitis caused by $B$. abortus was done using a caprine model in a study published by Anderson et al. (1986). Infection of erythrophagocytic trophoblasts was noted first with evidence of bacterial replication in the rough endoplasmic reticulum (RER) of these cell types. The infection then spread to the chorioallantoic periplacentomal trophoblasts and the interplacentomal chorioallantoic trophoblasts. Necrosis of infected trophoblasts resulted in the formation of ulcerated membranes, and the bacteria were then able to spread to the placentomal capillaries then to the perivascular connective tissue of chorionic villi. Towards the end of the experiment when abortion was imminent, severe vasculitis and separation of the maternal and fetal epithelium at the microvillus border was observed.

Actual fetal infection is thought to occur via aspiration of amniotic fluid containing the $B$. abortus in a process proposed to be exacerbated by anoxia secondary to placentitis (López et al., 1984). The most common fetal lesions are fibrinous pleuritis, mild peritonitis, and pericarditis characterized by infiltration of neutrophils, lymphocytes and plasma cells with diffuse congestion in the pericardium and visceral pleura (Xavier et al., 2009).

\section{Vaccination for Brucellosis}

Vaccination has been cited by the US Centers for Disease Control (CDC) as the number one public health achievement for the $20^{\text {th }}$ century. With the objective of preventing disease, the basic concept of vaccination is to induce protective immunity to a pathogen by generating memory either via antibody production or a cell-mediated immune response. At the very minimum, a vaccine should induce protective immunity that mimics protection induced by natural infection (Olsen, 2013).

Understanding the natural response of the host to a pathogen is the first step to vaccine development. To this end, the murine experimental model has long been used to evaluate 
vaccines to Brucella and to study its pathogenesis. It has served as a useful framework for understanding the bias in immune responses which, depending on the nature of the pathogen, may be dominated by humoral (Th2) or cell-mediated (Th1) responses (Brown et al., 1998; Grilló et al., 2012). In the case of brucellosis, the mouse model has provided much information on the molecular pathophysiology of the disease demonstrating a predominantly Th1-type response (Grilló et al., 2012). Although similar Th1-type outcomes have also been found with bovine immune responses, the strict dichotomy of Th cell responses found with mice is not commonly observed in cattle. In fact, both Th1- and Th2-type responses are induced with Brucella (Brown et al., 1998).

Both innate and adaptive immune responses are stimulated during Brucella infection, and vaccination can recapitulate such responses. Protective immunity is considered to be mediated through Th1-type responses by CD4 ${ }^{+} \mathrm{T}$-cells and cytotoxic responses by $\mathrm{CD} 8^{+} \mathrm{T}$ cells. Stimulation of the innate response occurs via engagement of the toll-like receptors (TLRs) and other pathogen recognition receptors on innate immune cells such as macrophages and dendritic cells that ultimately can influence the development of adaptive immunity (Olsen, 2013). Three TLRs have been identified and thought to be the primary mediators for stimulating host innate responses during Brucella infection. These include TLR2 activated by lipidated outer membrane proteins (L-Omp-16 and L-Omp-19); TLR4 activated by $B$. abortus LPS and unlipidated outer membrane proteins (U-Omp-16); and intracellular TLR9 activated by Brucella DNA. Activation of these TLRs results in a cascade of intracellular signaling culminating in the stimulation of transcription factors NF-KB and MAPK followed by the production of inflammatory cytokines (Oliveira et al., 2008; Oliveira et al., 2012). IL-12, IL-18, TNF- $\alpha$, and IFN- $\gamma$ are the cytokines mainly associated with the Th1-type response to Brucella infection. Infected macrophages produce IL-12 and IL-18, which polarizes the Th1 cell response and induces the proliferation of IFN- $\gamma$ producing T cells.(Rossetti, C. A. 2011) IFN- $\gamma$ activates macrophages to 
enhance their killing ability and the expression of surface antigens. Activated macrophages are the major source of TNF- $\alpha$, although it is also produced by T cells. TNF- $\alpha$ has diverse biologic properties as a potent mediator of the inflammatory response to bacterial infections and has also been shown to be necessary for facilitating macrophage killing of brucellae (Jiang et al., 1993; D'Andrea et al., 1995; Pier et al., 2004). Because brucellae are able to infect and survive long-term in both phagocytic and non-phagocytic cells, antibodies are unable to provide complete protection during infection, particularly against the more virulent strains (Vitry et al., 2014). Host response after vaccination is strongly associated with vaccine formulation and vaccine administration. Vaccine administration can be differentiated based on frequency of administration and route of administration.

\subsection{Live B. abortus strain 19 (S19) vaccine}

The S19 vaccine is a live Brucella vaccine designed for use in cattle, and was developed from a spontaneously attenuated mutant discovered in 1923 (Buck, 1930). It is the most effective vaccine produced to date, and it serves as the reference standard for all other Brucella vaccines. Although vaccination with $\mathrm{S} 19$ increases resistance to $B$. abortus, it does not induce sterilizing immunity and S19's efficacy is estimated to be $70 \%$ (Lubroth et al., 2007). The S19 vaccine is normally given to female calves aged between 3 and 6 months as a single subcutaneous dose of $5-8 \times 10^{10}$ viable organisms. Because this vaccine develops persistent antibody titers, brucellae may be excreted into milk and is abortive in pregnant cattle (Stevens et al., 1994). For this reason, when administered to adult cattle, a reduced dose of from $3 \times 10^{8}$ to $3 \times 10^{9}$ organisms are administered subcutaneously or two doses of $5 \times 10^{9}$ viable organisms given by the conjunctival route can be used (World Animal Health Organization, 2014; Chand et al., 2015). This alternative produces protection without a persistent antibody response, and 
reduces the risks of abortion and excretion in milk when vaccinating adult cattle (World Animal Health Organization, 2014).

S19 has also been tested in wildlife. Controlled studies of S19-vaccinated pregnant bison showed high rates of abortion with protection rates less than seen with similarly vaccinated cattle (Davis et al., 1991). S19 vaccination of bison calves also proved ineffective when the same heifers were challenged two years later during pregnancy showing similar susceptibility to abortions as unvaccinated control heifers (Davis and Elzer, 2002). S19 vaccination has also been used in elk for ballistic vaccination with efficacy against challenge of only $30 \%$ (Olsen et al., 2006).

A significant disadvantage of $\mathrm{S} 19$ is its smooth phenotype making it difficult to distinguish between vaccinated and naturally infected animals using common serological diagnostic tests. Safety poses another concern as S19 can cause abortion if used in pregnant cattle, and it is fully virulent for humans (Yang et al., 2013).

\subsection{Live $B$. abortus strain $R B 51$ vaccine}

The Brucella RB51 vaccine is a spontaneous rough mutant selected after repeated in vitro passages of $B$. abortus 2308 (USDA challenge strain) on media containing rifampin and penicillin (Schurig et al., 1991). The lack of the O-LPS means that vaccinated cattle are unable to produce a positive serological response using conventional testing methods; hence, using RB51 allows to distinguish vaccinated animals from those naturally infected, which is particularly important if the goal of vaccination is eradication. Eradication programs often use a test and slaughter policy and are useful in countries with efficient veterinary services, well-controlled herds, and low disease prevalence (Moriyón et al., 2004).

RB51 vaccination of cattle is efficacious in preventing Brucella-induced abortion or fetal infection and when compared to S19, it is relatively safe (Olsen, 2000). Vaccination is normally 
done in calves between 4 and 12 months of age. The vaccine's efficacy is similar to that of S19vaccinated cattle (Olsen, 2000; Yang et al., 2013).

The safety and efficacy of RB51 has also been tested in wildlife. Several studies done in bison have had different outcomes with some studies showing reduced safety in pregnant bison (Palmer et al., 1996; Olsen et al., 1997), and in another study (Davis and Elzer, 1999), no abortions or tissue colonization attributed to the vaccine were found. RB51 is considered safe for bison since it has been used in numerous private herds and in Yellowstone National Park for a number of years with no major reported problems (Davis and Elzer, 2002). Efficacy studies with RB51 in bison have shown variable results. While a single dose provided some level of protection from abortion and uterine infection (Olsen et al., 2003), the use of a booster dose provides even greater protection (Olsen and Johnson, 2012; Olsen et al., 2015). Others have found that RB51 was not efficacious in bison (Davis and Elzer, 2002). Studies examining the efficacy of RB51 vaccine in elk, reindeer, and caribou have shown that it also conferred poor protection against abortion (Kreeger et al., 2002b; Davis and Elzer, 2002; Olsen et al., 2006).

Brucella RB51 has a major drawback in that not only is it virulent to humans, but is also resistant to the antibiotic rifampin, one of the most potent and effective antibiotics used for treating brucellosis.

\subsection{Live B. melitensis strain Rev 1 vaccine}

Rev 1 is used to vaccinate against $B$. melitensis infection in sheep and goats, and is considered the best vaccine available for the prophylaxis of brucellosis in small ruminants (Blasco, 1997). Rev 1 vaccination is recommended for lambs and kids between 3 and 6 months of age given as a single subcutaneous or conjunctival inoculation. The standard dose is between $0.5 \times 10^{9}$ and $2.0 \times 10^{9}$ viable organisms. Subcutaneous vaccination produces strong interferences in serological tests and is not recommended in combined eradication programs. 
Conjunctival administration produces similar protection without inducing a persistent antibody response, thus facilitating the application of eradication programs combined with vaccination (World Animal Health Organization, 2014). Rev 1 is not safe for use in pregnant animals and high rates of abortion are induced in pregnant animals even with reduced doses of vaccine administered via conjunctival inoculation (Zundel et al., 1992).

Like other live Brucella vaccines, Rev 1 is virulent for humans and care must be taken to avoid the risk of contaminating the environment or causing human infection (World Animal Health Organization, 2014).

\section{Recent Advances in Brucella Vaccine Development}

\subsection{Modification of current vaccines}

Several studies have been done on existing vaccines to modify them with the objective being able to distinguish animals vaccinated with smooth brucellosis vaccines or to improve the vaccine's efficacy. For example, S19 has been successfully modified with a DIVA (differentiating infected from vaccinated animals) gene to easily identify vaccinates. One such strain, referred to as M1-luc, offered protection comparable to S19 when tested in cattle (Fiorentino et al., 2008). Attempts to modify M1-luc by deleting most of omp19 with the intent to further attenuate this strain produced positive results in mice, but could not be replicated in the natural host. (Fiorentino et al., 2008). Modification of the RB51 vaccine by overexpression of a known protective antigen, Cu/Zn SOD, also increased protection when compared to RB51 in mice (Vemulapalli et al., 2000). However, its use in bison proved to be less efficacious than RB51 for protection against abortion and uterine infection (Olsen et al., 2009).

An interesting alternative to modifying the current conventional vaccines is priming cattle with S19 and boosting with RB51 (Dorneles et al., 2015). Both pregnant and non-pregnant 
heifers were boosted with RB51 to examine whether T cell responses could be enhanced; however, no increases in $\mathrm{CD}^{+}$or $\mathrm{CD} 8^{+} \mathrm{T}$ cell proliferation or percentage of IFN- $\gamma^{+} \mathrm{T}$ cells were observed relative to $\mathbf{S} 19$ only vaccines. Abortion challenge studies were not performed.

\subsection{Subunit vaccines}

The major constraints related to existing Brucella vaccines are related to virulence, the inability to provide sterile immunity, and for $\mathbf{S 1 9}$, the inability to readily distinguish infected from vaccinated animals. The availability of the genomic sequences for pathogenic Brucella spp. and their hosts has allowed for better understanding of the host-pathogen interactions and allows the discovery of subunit antigens several of which have been targeted for vaccine development (Gomez et al., 2013). Subunit vaccines commonly use a purified protein or DNA approach to stimulate immune responses in animals (Yang et al., 2013). As these subunit vaccines are nonviable and not infectious, they cannot cause disease and are therefore safer than live vaccines. They also have the advantage of protecting against multiple Brucella species because of their extensive gene homologies (Yang et al., 2013). Several subunit Brucella antigens have been tested as potential vaccines (Gomez et al., 2013).

However, it is challenging to evaluate subunit Brucella vaccines in livestock due to the high cost of maintaining these animals under biosafety level 3 containment for challenge studies, the absence of well-defined inbred animal populations, and often the limited availability of immunological reagents to further understand mechanisms of protection in livestock. Hence, the mouse model is often used for evaluating subunit Brucella vaccines as in the case for those developed using outer membrane proteins (Omps) and ribosomal proteins having varying degrees of success (Delpino et al., 2007b; Pasquevich et al., 2009; Yang et al., 2011). The results of these studies showed that such antigens were generally less effective than existing live vaccines, and not surprisingly, more than one dose was required to achieve the protection (Yang et al., 2013). A subunit (acellular) vaccine containing OMPs and LPS for B. ovis was 
tested in its natural host, and when delivered subcutaneously in poly ( $\varepsilon$-caprolactone) microparticles, it conferred similar protection as the Rev 1 vaccine (Da Costa Martins et al., 2010).

DNA vaccines consist of a plasmid DNA, expressing a gene of interest (in this case a protective antigen) under the transcriptional control of a promoter. The encoded antigen is transcribed and translated after being injected into the host, thus enabling the APCs to process and present the antigen in vivo to stimulate a specific immune response (Dhama et al., 2008). This alternative vaccine strategy could potentially offer many benefits including high safety and efficacy as well as stability at room temperature (Olsen, 2013). Because specific genes are selected, these vaccines can be designed to be multivalent and the DIVA strategy can also be employed by inserting marker genes (Dhama et al., 2008).

Several attempts have been made to develop DNA vaccines for brucellosis with the first challenge being to achieve the antigen expression. DNA vaccines for Brucella have been tested in mice following intramuscular administration (Kurar and Splitter, 1997); however, though immune responses were elicited, none have been found to offer levels of protection similar to existing live vaccines (Yang et al., 2013). Studies of DNA Brucella vaccines in the natural host are limited; however, several have been successfully tested in cattle (Sáez et al., 2008; Hu et al., 2009) and bison (Clapp et al., 2011a). With multiple vaccine doses, these studies have yielded promising results. Further investigation is necessary to develop a successful vaccine for use in the natural host.

\subsection{Live Brucella vaccines}

To date, live Brucella vaccines have provided the best protective response against infection and abortion. The development of new live Brucella vaccines needs to take into consideration safety issues both for the animal host and for humans administering the vaccine. 
Of course, it should provide a better protective response against both infection and abortion than the conventional livestock vaccines. When developing a live vaccine, the caveat is to generate a strain which can sufficiently persist in the host to provoke an appropriate adaptive immune response, while simultaneously exhibit reduced virulence to render it safe. Another consideration is that the Brucella LPS is very immunogenic, and its retention is believed to be important for contributing to protective immunity. Indeed, an attribute of S19 vaccine is its LPS, but at the same time, smooth vaccines will require the incorporation of a DIVA strategy to ensure vaccinated animals can be distinguished from those naturally infected (Yang et al., 2013; McGiven et al., 2015).

The mutation of known virulence genes to inactivate them is the traditional method applied to the development of live attenuated vaccines (Yang et al., 2013). In Brucella, some virulence factors are essential for invasion of the host cell, whereas others are crucial to avoid elimination by the host. They allow Brucella spp. to survive and proliferate within its replicative vacuole and enable the bacteria to escape detection by the host immune system (Fugier et al., 2007; de Figueiredo et al., 2015). Several vaccine candidates have been and continue to be identified and require further evaluation to determine suitability in the natural host (Clapp et al., 2011b; Izadjoo et al., 2004; Yang et al., 2006; Yang et al., 2010).

\section{Mucosal Vaccination as an Alternative Route of Brucella Vaccine Administration}

While Brucella species do not reside in the gut, oral exposure is a common route of infection both for animals and humans (Delpino et al., 2007a). Animals usually smell and lick fetal and placental tissues subsequent to Brucella-induced abortions. Among humans, Brucella infection is frequently acquired through consumption of raw or undercooked meat or from

unpasteurized dairy products (Delpino et al., 2007a; Godfroid et al., 2011). Because the 
Brucella pathogen first comes into contact with its host via a mucosal surface, the administration of a parenteral vaccine may not optimally induce protective immunity at mucosal surfaces, and this may contribute to the more likely establishment of infection. The use of a mucosal vaccine strategy which activates multiple arms of innate and adaptive immune systems may provide better results than currently observed (Belyakov and Ahlers, 2009). Such mucosal approaches have been found to be effective for cattle during DNA vaccination trials where mucosal vaccination provided a superior response compared to the parenteral route (Loehr et al., 2001; Babiuk et al., 2003).

\subsection{Oral vaccination}

Oral vaccines have several advantages over conventional parenteral vaccines: 1) ease of administration; 2) are needle-free improving safety; and 3) do not require trained personnel to administer the vaccine. Certainly, oral vaccines are subject to enzymatic and proteolytic degradation in the gastrointestinal tract which can compromise the vaccine's immunogenicity (Sedgmen et al., 2004), but pill or entrapment formulations are available to counter these natural processes.

Despite the fact that oral infection of livestock is frequent, few studies have tested oral administration of existing Brucella vaccines in cattle. Interestingly, oral S19 vaccination proved to be equally effective to s.c. vaccination in protecting pregnant heifers against Brucella-induced abortion (Nicoletti and Milward, 1983; Nicoletti, 1984). RB51 has also been tested in cattle with significant protection against abortion and colonization observed similar to s.c. RB51 (Elzer et al., 1998). Oral vaccination of red deer as a model for elk using both S19 and RB51 has been tested. Significant reduction in splenic colonization compared with the controls was observed (Arenas-Gamboa et al., 2009a; Arenas-Gamboa et al., 2009b).

An experimental live $B$. melitensis vaccine has been tested in a mouse model and found to provide a protective response against nasal challenge (Clapp et al., 2011b). Alternatively, 
different approaches using $\gamma$-irradiation to inactive wild-type Brucella as done with B. neotomae showed protection against systemic challenges in orally vaccinated mice (Dabral et al., 2014). These encouraging results warrant further research in the development of an oral vaccine as an alternative to the traditional parenteral vaccines.

\subsection{Nasal vaccination}

Brucella can also infect via the upper respiratory tract which may be also considered as an alternative route for vaccination of livestock. In fact, Brucella exposure to livestock can occur via ingestion or inhalation of microorganisms present in the placenta, associated fluids, and the aborted fetus which contain large numbers of the brucellae (Smith et al., 1961).

The intranasal (IN) route of vaccination is one of the most promising routes of vaccine administration with several advantages including the presence of a large, porous, highly vascularized surface area available for vaccine deposition and absorption. By employing this route, concerns regarding enzymatic/proteolytic degradation can be avoided.

IN immunization has been studied in lambs for use against intestinal parasites and have shown strong immune response and significant protection being induced relative to controls (Mohamed et al., 2013). Studies of the immune response in cattle following IN or s.c. vaccination have revealed that the vaccine delivery mechanism possibly plays a role in the immune response with mucosal vaccination inducing both systemic and mucosal immune responses. In one study, soluble antigen plus cholera toxin (CT) adjuvant administered by the IN route elicited both vaccine-specific IgA production and lymphocyte proliferation whereas S.C administration of the same antigen with Freund's adjuvant failed to produce an antigen specific IgA response (Rebelatto et al., 2001a). In another study where the IN vaccine was delivered in encapsulated microparticles, high levels of IgG1 antibody in serum, nasal secretions, and to a lesser extent saliva were observed in IN vaccinated calves (Rebelatto et al., 2001b). 
Though not yet reported in cattle, the use of recently developed IN vaccine administration strategies using subunit and live vaccines can possibly be successfully employed for Brucella vaccination, and several promising studies in mice have been completed (Yang et al., 2007; Clapp et al., 2016; Tabynov et al., 2014).

\subsection{Delivery of Antigens for Mucosal Vaccination}

The advantages of using live vaccines are that they often can produce natural infections by targeting mucosal tissues as part of their normal means of infection. However, subunit vaccines often do not possess the properties to be adsorbed or to reach their target cells. Consequently, for these vaccines to be successful, special delivery and targeting systems need to be adapted to overcome these limitations (Almeida and Souto, 2007). The use of controlled release formulations protects the vaccine over an extended period of time from degradation and elimination, and can facilitate the delivery of the vaccine to the desired site of action. Particulate carrier systems such as microencapsulation and nanoencapsulation techniques have been developed, involving coating and isolating bioactive substances in envelopes of protective materials until such time as their activity is needed. Polymeric hydrogels, nanoparticles and microspheres, and lipid-based drug delivery systems such as fat emulsions, liposomes and solid lipid nanoparticles (SLN) are all examples of particulate carrier systems for protein delivery (Almeida and Souto, 2007).

Recently, there has been significant progress in developing nanoparticle-based delivery systems. This could be of particular importance for Brucella vaccine development as the cellmediated immunity, required for protection, can be induced using such methods. The value in these systems lies in their ability, not only to encapsulate a wide range of antigen species, but also support the addition of modules that may enable selective targeting to and uptake by desired cell types including the introduction of adjuvants to enhance immune responses. In 
addition, these can be modified to include elements that will deliver internalized antigens to the appropriate intracellular compartments. Moreover, these particles can be derivatized with elements that can aid in penetrating epithelial barriers and surviving the gastrointestinal tract environment (Fahmy et al., 2008). This was evident by the protection conferred by orally immunizing red deer with microencapsulated S19 vaccine, which induced enhanced humoral and cellular immune responses (Arenas-Gamboa et al., 2009a).

\section{Conclusions}

Brucellosis remains an important public health concern both in the US where natural reservoirs are present, and in many other countries where eradication is often not economically feasible and because of a lack of the means to develop and implement vaccination controls. Recent civil unrests in different parts of the world, and the subsequent increase in human and animal migration have resulted in the re-emergence of this disease in areas previously considered to be brucellosis-free (Seleem et al., 2010; Hotez et al., 2012).

Vaccination of susceptible animals is the most feasible way to reduce the zoonotic transmission of this disease and to reduce the serious economic losses caused by outbreaks in domestic animal herds. An understanding of the Brucella pathogen and how it interacts to its host is important when developing a vaccine and when implementing a vaccination strategy. Both the formulation of the vaccine and method of delivery are important for consideration, particularly exploring the possibility of mucosal routes of vaccination. Such attention might very well be the key to producing a safe brucellosis vaccine which provides superior levels of protection to those currently used. 


\section{Acknowledgements}

Financial Support: Research funds were provided by USDA-NIFA 2013-01165. 


\section{References}

Almeida, A.J., Souto, E., 2007. Solid lipid nanoparticles as a drug delivery system for peptides and proteins. Adv. Drug Deliv. Rev. 59, 478-490.

Anderson, T.D., Meador, V.P., Cheville, N.F., 1986. Pathogenesis of placentitis in the goat inoculated with Brucella abortus. I. Gros and histologic lesions. Vet. Patho. 23, 219-3.

Arenas-Gamboa, A.M., Ficht, T.A., Davis, D.S., Elzer, P.H., Kahl-McDonagh, M., WongGonzalez, A., Rice-Ficht, A.C., 2009a. Oral vaccination with microencapsuled strain 19 vaccine confers enhanced protection against Brucella abortus strain 2308 challenge in red deer (Cervus elaphus elaphus). J. Wildl. Dis. 45, 1021-9.

Arenas-Gamboa, A.M., Ficht, T.A., Davis, D.S., Elzer, P.H., Wong-Gonzalez, A., Rice-Ficht, A.C., 2009b. Enhanced immune response of red deer (Cervus elaphus) to live RB51 vaccine strain using composite microspheres. J. Wildl. Dis. 45, 165-73.

Ariza, J., Corredoira, J., Pallares, R., Viladrich, P.F., Rufi, G., Pujol, M., Gudiol, F., 1995. Characteristics of and risk factors for relapse of brucellosis in humans. Clin. Infect. Dis. 20, 1241-9.

Ashford, D.A., di Pietra, J., Lingappa, J., Woods, C., Noll, H., Neville, B., Weyant, R., Bragg, S.L., Spiegel, R.A., Tappero, J., Perkins, B.A., 2004. Adverse events in humans associated with accidental exposure to the livestock brucellosis vaccine RB51. Vaccine 22, 25-26.

Aznar, M.N., Samartino, L.E., Humblet, M.F., Saegerman, C., 2014. Bovine brucellosis in Argentina and bordering countries: update. Transbound. Emerg. Dis. 61, 121-33.

Babiuk, L.A., Pontarollo, R., Babiuk, S., Loehr, B., van Drunen Littel-van den Hurk, S., 2003. Induction of immune responses by DNA vaccines in large animals. Vaccine 21, 649-58.

Belyakov, I.M., Ahlers, J.D., 2009. What role does the route of immunization play in the generation of protective immunity against mucosal pathogens? J. Immunol. 183, 6883-92.

Blasco, J.M., 1997. A review of the use of $B$. melitensis Rev 1 vaccine in adult sheep and goats. Prev Vet Med. 31, 275-83.

Blasco, J.M., Molina-Flores, B., 2001. Control and eradication of Brucella melitensis infection in sheep and goats. Vet. Clin. North Am. Food Anim. Pract. 27, 95-104

Bonfoh, B., Kasymbekov, J., Dürr, S., Toktobaev, N., Doherr, M.G., Schueth, T., Zinsstag, J., Schelling, E., 2012. Representative seroprevalences of brucellosis in humans and livestock in Kyrgyzstan. Ecohealth 9, 132-8.

Brown, W.C., Rice-Ficht, A.C., Estes, D.M., 1998. Bovine type 1 and type 2 responses. Vet. Immunol. Immunopathol. 63, 45-55. 
Buck, J.M., 1930. Studies of vaccination during calfhood to prevent bovine infectious abortion. J. Agr. Res. 41, 667-89.

Celli, J., de Chastellier, C., Franchini, D.M., Pizarro-Cerda, J., Moreno, E., Gorvel, J.P., 2003. Brucella evades macrophage killing via VirB-dependent sustained interactions with the endoplasmic reticulum. J. Exp. Med. 198, 545-56.

Chand, P., Chhabra, R., Nagra, J., 2015. Vaccination of adult animals with a reduced dose of Brucella abortus S19 vaccine to control brucellosis on dairy farms in endemic areas of India. Trop. Anim. Health. Prod. 47, 29-35.

Clapp, B., Walters, N., Thornburg, T., Hoyt, T., Yang, X., Pascual, D.W., 2011a. DNA Vaccination of bison to brucellar antigens elicits elevated antibody and IFN-y responses. J. Wildl. Dis. 47, 501-510.

Clapp, B., Skyberg, J.A., Yang, X., Thornburg, T., Walters, N., B., Pascual, D.W., 2011b. Protective live oral brucellosis vaccines stimulate Th1 and Th17 cell responses. Infect. Immun. 79, 4165-4174.

Clapp, B., Yang, X., Thornburg, T., Walters, N., Pascual, D.W., 2016. Nasal vaccination stimulates $\mathrm{CD}^{+} \mathrm{T}$ cells for potent protection against mucosal Brucella melitensis challenge. Immunol. Cell Biol. (In press).

Clifford, J., 2008. 2008 United States Animal Health Report. USDA. Agri. Inf. Bull. USDA 806, 34-37.

Da Costa Martins, R., Irache, J.M., Blasco, J.M., Muñoz, M.P., Marín, C.M., Jesús Grilló, M., Jesús De Miguel, M., Barberán, M., Gamazo, C., 2010. Evaluation of particulate acellular vaccines against Brucella ovis infection in rams. Vaccine $28,3038-46$.

Dabral, N., Martha-Moreno-Lafont, Sriranganathan, N., Vemulapalli, R., 2014. Oral immunization of mice with g-irradiated Brucella neotomae induces protection against intraperitoneal and intranasal challenge with virulent B. abortus 2308. PLoS One 9, e107180.

D'Andrea, A., Ma, X., Aste-Amezaga, M., Paganin, C., Trinchieri, G., 1995. Stimulatory and inhibitory effects of interleukin (IL)-4 and IL-13 on the production of cytokines by human peripheral blood mononuclear cells: priming for IL-12 and tumor necrosis factor alpha production. J. Exp. Med. 181, 537-46.

Davis, D.S., Templeton, J.W., Ficht, T.A., Huber, J.D., Angus, R.D., Adams, L.G., 1991. Brucella abortus in bison. II. Evaluation of strain 19 vaccination of pregnant cows. J. Wildl. Dis. 27, 258-64.

Davis, D.S., Elzer, P.H., 1999. Safety and efficacy of Brucella abortus RB51 vaccine in adult American bison (Bison bison). Proc. United States Anim. Health Assoc 103, 154-8.

Davis, D.S., Elzer, P.H., 2002. Brucella vaccines in wildlife. Vet. Microbiol. 90, 533-544. 
de Figueiredo, P., Ficht, T.A., Rice-Ficht, A., Rossetti, C.A., Adams, LG., 2015. Pathogenesis and immunobiology of brucellosis: review of Brucella-host interactions. Am. J. Pathol. 185, 1505-17.

Delpino, M.V., Marchesini, M.I., Estein, S.M., Comerci, D.J., Cassataro, J., Fossati, C.A., Baldi, P.C., 2007a. A bile salt hydrolase of Brucella abortus contributes to the establishment of a successful infection through the oral route in mice. Infect. Immun. 75, 299-305.

Delpino, M.V., Estein, S.M., Fossati, C.A., Baldi, P.C., Cassataro, J., 2007b. Vaccination with Brucella recombinant DnaK and SurA proteins induces protection against Brucella abortus infection in BALB/c mice. Vaccine 25, 6721-9.

Dhama, K., Mahendran, M., Gupta, P.K., Rai, A., 2008. DNA vaccines and their applications in veterinary practice: current perspectives. Vet. Res. Commun. 32, 341-56.

Dorneles, E.M.S., Teixeira-Carvalho, A., Araújo, M.S.S., Sriranganathan, N., Lage, A.P., 2015. Immune response triggered by Brucella abortus following infection or vaccination. Vaccine 33, 3659-66.

Elzer, P.H., Enright, F.M., Colby, L., Hagius, S.D., Walker, J.V., Fatemi, M.B., Kopec, J.D., Beal, V.C.J., Schurig, G.G., 1998. Protection against infection and abortion induced by virulent challenge exposure after oral vaccination of cattle with Brucella abortus strain RB51. Am. J. Vet. Res. 59, 1575-8.

Fahmy, T.M., Demento, S.L., Caplan, M.J., Mellman, I., Saltzman, W.M., 2008. Design opportunities for actively targeted nanoparticle vaccines. Nanomedicine 3, 343-55.

Fiorentino, M.A., Campos, E., Cravero, S., Arese, A., Paolicchi, F., Campero, C., Rossetti, O., 2008. Protection levels in vaccinated heifers with experimental vaccines Brucella abortus M1-luc and INTA 2. Vet. Microbiol. 132, 302-11.

Franco, M.P., Mulder, M., Smits, H.L., 2007. Persistence and relapse in brucellosis and need for improved treatment. Trans. R. Soc. Trop. Med. Hyg. 101, 854-5.

Fugier, E., Pappas, G., Gorvel, J., 2007. Virulence factors in brucellosis: implications for aetiopathogenesis and treatment. Expert Rev. in Mol. Med. 9, 1-10.

Glynn, M.K., Lynn, T.V., 2008. Brucellosis. J. Am. Vet. Med. Assoc. 233, 900-8.

Godfroid, J., Nielsen, K., Saegerman, C., 2010. Diagnosis of brucellosis in livestock and wildlife. Croat. Med. J. 51, 296-305.

Godfroid, J., Scholz, H.C., Barbier, T., Nicolas, C., Wattiau, P., Fretin, D., Whatmore, A.M., Cloeckaert, A., Blasco, J.M., Moriyon, I., Saegerman, C., Muma, J.B., Al Dahouk, S., Neubauer, H., Letesson, J.J., 2011. Brucellosis at the animal/ecosystem/human interface at the beginning of the 21st century. Prev. Vet. Med 102, 118-31.

Godfroid, J., Garin-Bastuji, B., Saegerman, C., Blasco, J.M., 2013. Brucellosis in terrestrial wildlife. Rev. Sci. Tech. 32, 27-42. 
Gomez, G., Adams, L.G., Rice-Ficht, A., Ficht, T.A., 2013. Host-Brucella interactions and the Brucella genome as tools for subunit antigen discovery and immunization against brucellosis. Front. Cell and Infect. Microbiol. 3, 7-12-2015-17.

Grilló, M., Blasco, J., Gorvel, J.P., Moriyón, I., Moreno, E., 2012. What have we learned from brucellosis in the mouse model? Vet. Res. 43, 29.

Guzmán-Verri, C., Manterola, L., Sola-Landa, A., Parra, A., Cloeckaert, A., Garin, J., Gorvel, J.P., Moriyón, I., Moreno, E., López-Goñi, I., 2002. The two-component system BvrR/BvrS essential for Brucella abortus virulence regulates the expression of outer membrane proteins with counterparts in members of the Rhizobiaceae. Proc. Natl. Acad. Sci. U S A 99, 12375-80.

Haag, A.F., Myka, K.K., Arnold, M.F., Caro-Hernández, P., Ferguson, G.P., 2010. Importance of lipopolysaccharide and cyclic $\beta-1,2-$ glucans in Brucella-mammalian infections. Int. J. Microbiol. doi:10.1155/2010/124509, 4-12-2014.

Hotez, P.J., Savioli, L., Fenwick, A., 2012. Neglected tropical diseases of the Middle East and North Africa: review of their prevalence, distribution, and opportunities for control. PLoS Negl. Trop. Dis. 6, e1475.

Hu, X.D., Yu, D.H., Chen, S.T., Li, S.X., Cai, H., 2009. A combined DNA vaccine provides protective immunity against Mycobacterium bovis and Brucella abortus in cattle. DNA Cell. Biol. 28, 191-9.

Izadjoo, M.J., Bhattacharjee, A.K., Paranavitana, C.M., Hadfield, T.L., Hoover, D.L., 2004. Oral vaccination with Brucella melitensis WR201 protects mice against intranasal challenge with virulent Brucella melitensis 16M. Infect. Immun. 72, 4031-9.

Jiang, X., Leonard, B., Benson, R., Baldwin, C.L., 1993. Macrophage control of Brucella abortus: role of reactive oxygen intermediates and nitric oxide. Cell. Immunol. 151, 309-19.

Köse, Ş., Serin, S.S., Akkoçlu, G., Kuzucu, L., Ulu, Y., Ersan, G., Oğuz, F., 2014. Clinical manifestations, complications, and treatment of brucellosis: evaluation of 72 cases. Turk. J. Med. Sci. 44, 220-3.

Kreeger, T.J., Cook, W.H., Edwards, P.H., Elzer, P.H., Olsen, S.C., 2002a. Brucella abortus Strain RB51 vaccination in Elk. II. Failure of high dosage to prevent abortion. J. Wildl. Dis. 38, 27-31.

Kreeger, T.J., DeLiberto, T.J., Olsen, S.C., Edwards, W.H., Cook, W.E., 2002b. Safety of Brucella abortus strain RB51 vaccine in non-target ungulates and coyotes. J. Wildl. Dis. 38, 552-7.

Kurar, E., Splitter, G.A., 1997. Nucleic acid vaccination of Brucella abortus ribosomal L7/L12 gene elicits immune response. Vaccine 15, 17-18.

Leiser, O.P., Corn, J.L., Schmit, B.S., Keim, P.S., 2013. Feral swine brucellosis in the United States and prospective genomic techniques for disease epidemiology. Vet. Microbiol. 166, 1-10. 
Loehr, B.I., Rankin, R., Pontarollo, R., King, T., Willson, P., Babiuk, L.A., van Drunen Littel-van den Hurk,S., 2001. Suppository-mediated DNA immunization induces mucosal immunity against Bovine Herpesvirus-1 in Cattle. Virology 289, 327-333.

López, A., Hitos, F., Pérez, A., Navarro-Fierro, R.R., 1984. Lung lesions in bovine fetuses aborted by Brucella abortus. Can. J. Comp. Med. 48, $275-7$.

Lubroth, J., Rweyemamu, M.M., Viljoen, G., Diallo, A., Dungu, B., Amanfu, W., 2007. Veterinary vaccines and their use in developing countries. Rev. Sci. Tech. Off. Int. Epiz. 26, 179-201.

McGiven, J., Howells, L., Duncombe, L., Stack, J., Ganesh, N. V., Guiard, J., Bundle, D. R., 2015. Improved serodiagnosis of bovine brucellosis by novel synthetic oligosaccharide antigens representing the capping $\mathrm{m}$ epitope elements of Brucella O-polysaccharide. J. Clin. Micro. 53, 1204.

Memish, Z.A., Balkhy, H.H., 2006. Brucellosis and international travel. J. Travel Med. 11, 49-55.

Mohamed, F.E., Cruz, B.T., Gómez, S.M., González-González, G., Solano J, G., M.E., De Pablos, L.M., Corral-Caridad, M.J., Cuquerella, M., Osuna, A., Alunda, J.M., 2013. Intranasal immunization of lambs with serine/threonine phosphatase $2 \mathrm{~A}$ against gastrointestinal nematodes. Clin. Vaccine Immunol. 20, 1352-9.

Moriyón, I., Grilló, M.J., Monreal, D., González, D., Marín, C., López-Goñi, I., Mainar-Jaime, R.C., Moreno, E., Blasco, J.M., 2004. Rough vaccines in animal brucellosis: structural and genetic basis and present status. Vet. Res. 35, 1-38.

Neta, A.V.C., Mol, J.P.S., Xavier, M.N., Paixão, T.A., Lage, A.P., Santos, R.L., 2010. Pathogenesis of bovine brucellosis. Vet. J. 184, 146-155.

Nicoletti, P., Milward, F.W., 1983. Protection by oral administration of Brucella abortus strain 19 against an oral challenge exposure with a pathogenic strain of Brucella. Am. J. Vet. Res. 44, 1641-3.

Nicoletti, P., 1984. Vaccination of cattle with Brucella abortus strain 19 administered by differing routes and doses. Vaccine 2, 133-5.

Oliveira, S.C., de Oliveira, F.S., Macedo, G.C., de Almeida, L.A., Carvalho, N.B., 2008. The role of innate immune receptors in the control of Brucella abortus infection: toll-like receptors and beyond. Microbes Infect. 10, 1005-9.

Oliveira, S.C., de Almeida, L.A., Carvalho, N.B., Oliveira, F.S., Lacerda, T.L.S., 2012. Update on the role of innate immune receptors during Brucella abortus infection. Vet. Immunol. Immunop. $148,129-135$.

Olsen, S.C., 2000. Immune responses and efficacy after administration of a commercial Brucella abortus strain RB51 vaccine to cattle. Vet. Ther. 1, 183-91.

Olsen, S.C., 2013. Recent developments in livestock and wildlife brucellosis vaccination. Rev. Sci. Tech. 32, 207-17. 
Olsen, S.C., Johnson, C.S., 2012. Efficacy of dart or booster vaccination with strain RB51 in protecting bison against experimental Brucella abortus challenge. Clin. Vaccine Immunol. 19, 886-890.

Olsen, S.C., Cheville, N.F., Kunkle, R.A., Palmer, M.V., Jensen, A.E., 1997. Bacterial survival, lymph node pathology, and serological responses of bison (Bison bison)vaccinated with Brucella abortus strain RB51 or strain 19. J. Wildl. Dis. 33, 146-151.

Olsen, S.C., Jensen, A.E., Stoffregen, W.C., Palmer, M.V., 2003. Efficacy of calfhood vaccination with Brucella abortus strain RB51 in protecting bison against brucellosis. Res Vet Sci. 74, 17-22.

Olsen, S.C., Fach, S.J., Palmer, M.V., Sacco, R.E., Stoffregen, W.C., Waters, W.R., 2006. Immune Responses of elk to initial and booster vaccinations with Brucella abortus strain RB51 or 19. Clin. Vaccine Immunol. 13, 1098-1103.

Olsen, S.C., Boyle, S.M., Schurig, G.G., Sriranganathan, N.N., 2009. Immune responses and protection against experimental challenge after vaccination of bison with Brucella abortus strain RB51 or RB51 overexpressing superoxide dismutase and glycosyltransferase genes. Clin. Vaccine Immunol. 16, 535-40.

Olsen, S.C., McGill, J.L., Sacco, R.E., Hennager, S.G., 2015. Immune responses of bison and efficacy after booster vaccination with Brucella abortus strain RB51. Clin. Vaccine Imunol. 22, 440-7.

Palmer, M.V., Olsen, S.C., Gilsdorf, M.J., Philo, L.M., Clarke, P.R., Cheville, N.F., 1996. Abortion and placentitis in pregnant bison (Bison bison) induced by the vaccine candidate, Brucella abortus strain RB51. Am. J. Vet. Res. 57, 1604-7.

Pappas, G., Akritidis, N., Tsianos, E., 2005. Effective treatments in the management of brucellosis. Expert Opin. Pharmacother. 6, 201-9.

Pappas, G., Papadimitriou, P., Akritidis, N., Christou, L., Tsianos, E.V., 2006. The new global map of human brucellosis. Lancent Infect. Dis. 6, 91-9.

Pasquevich, K.A., Estein, S.M., García Samartino, C., Zwerdling, A., Coria, L.M., Barrionuevo, P., Fossati, C.A., Giambartolomei, G.H., Cassataro, J., 2009. Immunization with recombinant Brucella species outer membrane protein Omp16 or Omp19 in adjuvant induces specific CD4 ${ }^{+}$ and $\mathrm{CD}^{+} \mathrm{T}$ cells as well as systemic and oral protection against Brucella abortus infection. Infect. Immun. 77, 436-45.

Pier, G.B., Lyczak, J.B., Wetzler, L.M., 2004. Immunology, Infection and Immunity, ASM Press.

Plilo, C., Tedde, M.T., Orru, G., Addis, G., Lliciardi, M., 2015. Brucella suis infection in domestic pigs in Sardinia (Italy). Epidemiol. Infect. 143, 2170-7.

Rebelatto, M.C., Siger, L., Hogenesch, H., 2001a. Kinetics and type of immune response following intranasal and subcutaneous immunisation of calves. Res. Vet. Sci. 71, 9-15. 
Rebelatto, M.C., Guimond, P., Bowersock, T.L., HogenEsch, H., 2001b. Induction of systemic and mucosal immune response in cattle by intranasal administration of pig serum albumin in alginate microparticles. Vet. Immunol. Immunopathol. 83, 93-105.

Roop, R.M.2., Gaines, J.M., Anderson, E.S., Caswell, C.C., Martin, D.W., 2009. Survival of the fittest: how Brucella strains adapt to their intracellular niche in the host. Med. Microbiol. Immunol. 198, 221-38.

Rossetti, C.A., Galindo, C.L., Everts, R.E., Lewin, H.A., Garner, H.R., Adams, L.G., 2011. Comparative analysis of the early transcriptome of Brucella abortus- infected monocyte-derived macrophages from cattle naturally resistant or susceptible to brucellosis. Res. Vet. Sci. 91, 4051.

Sáez, D., Guzmán, I., Andrews, E., Cabrera, A., Oñate, A., 2008. Evaluation of Brucella abortus DNA and RNA vaccines expressing $\mathrm{Cu}-\mathrm{Zn}$ superoxide dismutase (SOD) gene in cattle. Vet Microbiol. 129, 396-403.

Scholz, H.C., Vergnaud, G., 2013. Molecular characterisation of Brucella species. Rev. Sci. Tech. 32, 149-62.

Schurig, G.G., Roop, R.M. II, Bagchi, T., Boyle, S., Buhrman, D., Sriranganathan, N., 1991. Biological properties of RB51; a stable rough strain of Brucella abortus. Vet. Microbiol. 28, 17188.

Sedgmen, B.J., Meeusen, E.N., Lofthouse, S.A., 2004. Alternative routes of mucosal immunization in large animals. Immunol. Cell Biol. 82, 10-16.

Seleem, M.N., Boyle, S.M., Sriranganathan, N., 2010. Brucellosis: a re-emerging zoonosis. Vet. Microbiol. 140, 392-8.

Smith, H., Keppie, J., Pearce, J.H., Fuller, R., Williams, A.E., 1961. The chemical basis of the virulence of Brucella abortus I. Isolation of $B$. abortus from bovine foetal tissue. Br. J. Exp. Pathol. 42, 631-7.

Smith, H., Keppie, J., Pearce, J.H., Wlitt, K., 1962a. The chemical basis of the virulence of Brucella abortus. IV. Immunogenic products from Brucella abortus grown in vivo and in vitro. Br. J. Exp. Pathol. 43, 538-48.

Smith, H., Williams, A.E., Pearce, J.H., Keppie, J., Harris-Smith, P.W., Fitz-George, R.B., Witt, K., 1962b. Foetal erythritol: a cause of the localization of Brucella abortus in bovine contagious abortion. Nature 193, 47-9.

Spink, W.W., Hall, J.W., Finstad, J., Mallet, E., 1962. Immunization with viable Brucella organisms. Results of a safety test in humans. Bull. World Health Organ. 26, 409-19.

Stevens, M.G., Hennager, S.G., Olsen, S.C., Cheville, N.F., 1994. Serologic responses in diagnostic tests for brucellosis in cattle vaccinated with Brucella abortus 19 or RB51. J. Clin. Microbiol. 32, 1065-6. 
Tabynov, K., Sansyzbay, A., Kydyrbayev, Z., Yespembetov, B., Ryskeldinova, S., Zinina, N., Assanzhanova, N., Sultankulova, K., Sandybayev, N., Khairullin, B., Kuznetsova , I., Ferko, B., Egorov, A., 2014. Influenza viral vectors expressing the Brucella OMP16 or L7/L12 proteins as vaccines against $B$. abortus infection. Virol. J. 11.

Vemulapalli, R., He, Y., Cravero, S., Sriranganathan, N., Boyle, S.M., Schurig, G.G., 2000. Overexpression of protective antigen as a novel approach to enhance vaccine efficacy of Brucella abortus strain RB51. Infect Immun. 68, 3286-9.

Vitry, M., Mambres, D.H., De Trez, C., Akira, S., Ryffel, B., Letesson, J.-., Muraillell, E., 2014. Humoral immunity and CD4 ${ }^{+}$Th1 cells are both necessary for a fully protective immune response upon secondary infection with Brucella melitensis. J. Immunol. 192, 3740-52.

Whatmore, A.M., 2009. Current understanding of the genetic diversity of Brucella, an expanding genus of zoonotic pathogens. Infect. Genet. Evol. 9, 1168-1184.

Williams, A.E., Keppie, J., Smith, H., 1964. The relation of erythritol usage to virulence in the Brucellas. J. Gen. Microbiol. 37, 285-92.

World Animal Health Organization, 2014. Manual of Diagnostic Tests and Vaccines for Terrestrial animals, World Animal Health Organization.

Xavier, M.N., Paixão, T.A., Poester, F.P., Lage, A.P., Santos, R.L., 2009. Pathological, immunohistochemical and bacteriological study of tissues and milk of cows and fetuses experimentally infected with Brucella abortus. J. Comp. Pathol. 140, 149-157.

Yang, X., Becker, T., Walters, N., Pascual, D.W., 2006. Deletion of znuA virulence factor attenuates Brucella abortus and confers protection against wild-type challenge. Infect. Immun. 74, 3874-9.

Yang, X., Walters, N., Robison, A., Trunkle, T., Pascual, D.W., 2007. Nasal immunization with recombinant Brucella melitensis bp26 and trigger factor with cholera toxin reduces $B$. melitensis colonization. Vaccine 25, 2261-8.

Yang, X., Thornburg, T., Walters, N., Pascual, D.W., 2010. AznuA 4 purE Brucella abortus 2308 mutant as a live vaccine candidate. Vaccine 28, 1069-74.

Yang, X., Skyberg, J.A., Cao, L., Clapp, B., Thornburg, T., Pascual, D.W., 2013. Progress in Brucella vaccine development. Front. Biol. (Beijing) 8, 60-77.

Yang, Y., Yin, J., Guo, D., Lang, X., Wang, X., 2011. Immunization of mice with recombinant Sadenosyl-L-homocysteine hydrolase protein confers protection against Brucella melitensis infection. FEMS Immunol. Med. Microbio. 61, 159-67.

Zundel, E., Verger, J.M., Grayon, M., Michel, R., 1992. Conjunctival vaccination of pregnant ewes and goats with Brucella melitensis Rev 1 vaccine: safety and serological responses. Ann. Rech. Vet. 23, 177-88. 